\title{
A Comparative Analysis of Student Performance in Lower Division Computer Science Courses in Face-to-Face Mode vs. Distance Learning Mode
}

\author{
Vladimir Briller and John D. Carpinelli \\ New Jersey Institute of Technology
}

\begin{abstract}
Computer engineering and computer science students at the New Jersey Institute of Technology (NJIT) take a two-course sequence on the fundamentals of computer science as parts of their plans of study. The two courses, CIS 113 and CIS 114, cover topics in computer system basics, algorithm design, data abstraction, programming languages, data structures, and program development and debugging. Students may take either course in face-to-face mode or in distance learning mode.
\end{abstract}

This paper presents an analysis of student performance in the two courses for both modes of instruction. The analysis covers course offerings from the Fall 1994 semester through the Spring 2001 semester and includes a population of over 5,700 students. This paper also analyzes variances in the performance among distance learning students. For some instructors, the student course passing rates were consistently higher than for the others. That, coupled with better scores on student evaluations, allowed us to emphasize the impact of teaching style and teaching methodologies on the course outcomes for the distance learning students.

\section{Introduction}

There are several studies of the performance of students in traditional, face-to-face courses offered in distance learning mode, for example [1]. In general, these studies show no significant difference in student performance between the two modes of instruction. However, they are typically limited to student performance in individual courses. They do not assess how well students retain the knowledge gained in these courses and how well they perform in subsequent courses that use this knowledge. In this study, we assess the performance of students in two freshman computer science courses. Both courses are offered in both face-to-face and distance learning modes. This study is a follow-up to a previous study by the authors that analyzed the performance of students in upper-division computer engineering courses [2].

Freshman computer science and computer engineering students at the New Jersey Institute of Technology take CIS 113 and CIS 114, Introduction to Computer Science I and II. The first course, CIS 113, covers basic concepts of computer systems, software engineering, algorithm design, programming languages and data abstraction. Students in this course use $\mathrm{C}++$ as the primary programming language. This course serves as a prerequisite for CIS 114, which covers 
program specifications, correctness and efficiency, data abstraction, basic aspects of simple data structures, internal searching and sorting, recursion, string processing and algorithmic analysis. When offered in face-to-face mode, each course meets for three hours of lecture per week, and one additional hour for laboratory work and problem solving. Students in the distance learning version of these courses do not have set meeting times, but follow roughly the same schedule of topics throughout the semester as their face-to-face counterparts.

The rest of this paper is organized as follows. The hypothesis and research design are presented next, followed by a description of the data collection and analysis procedures. Results are then given and discussed. A summary and recommendations for future work conclude this paper.

\section{Hypothesis and Research Design}

The researchers decided to use null hypothesis for the study: there is no difference between distance learning (DL) and face-to-face (FTF) student performance on CIS 113 and 114 courses. The researchers compared two groups of students who took the Introduction to Computer Science I (CIS 113) and II (CIS 114) courses; the former is a prerequisite for the latter. The study looked for the answers to the following research questions: Is there a difference in demographic or academic characteristics between DL and FTF students? Is there a correlation between students' performance on CIS 113 and 114? Is there a correlation between demographic or academic characteristics and performance on CIS 113 and 114? Is there a difference in overall academic performance between DL and FTF students? Is there a difference in performance of DL and FTF students on CIS 113 and 114? Is there a difference between subgroups of students in their performance on CIS 113 and 114? Is there a correlation between the mode of study and students' performance on CIS 113 and 114 ?

\section{Procedures}

The researchers compared DL and FTF groups' demographic and academic characteristics to see if there were any differences between them. Then, correlation analysis was conducted to see if there was a relation between students' demographic or academic characteristics and their scores on CIS 113 and CIS 114. Finally, T-tests were performed to see if there were any statistically significant differences in the groups' performance in CIS 113 and in CIS 114.

\section{Limitations and Delimitations of the Study}

One of the study's limitations is the fact that students were not randomly selected to the groups; the selection was based only on their willingness to be in distance learning or in face-to-face course. Such self-selection was explained by non-academic reasons, such as a conflict of scheduling with other courses or a part-time job, or the level of familiarity with on-line education, thus self-selection could not have had any impact on the academic performance. 
As a delimitation, the authors assumed that students' learning styles did not have a significant effect on the outcomes of either course.

\section{Results}

A population of 5,743 students who had taken freshman computer science CIS 113 and CIS 114 courses in Fall 1994 through Spring 2001 was analyzed. 4,945 students have taken the courses in face-to-face (FTF) mode and 798 in distance learning (DL) mode. The groups have similar demographic composition and almost identical average SAT Math scores, 582 for FTF and 583 for DL; average SAT Verbal scores were higher for DL students - 531 vs. 506 for FTF. Cumulative college grade point average (GPA) was higher for FTF students -2.57 vs. 2.41. The difference in cumulative GPA is statistically significant ${ }^{1}$; analyses of correlations have not found any correlations between student SAT scores and cumulative GPA's or between student SAT scores and their CIS 113/114 grades.

Two types of analyses were conducted: (1) analysis of correlations between students' mean grades on courses taken in different modes and (2) analysis of differences between students' mean grades on CIS 113 and CIS 114 courses taken in each mode. The results of the analysis of correlations between the students who took CIS 113 and 114 in different modes are shown in Table 1.

Table 1. Test of correlations between the mean grades of students who took CIS 113 and 114 in FTF and DL modes in 1994-2001. Asterisks denote groups with statistically significant correlations.

\begin{tabular}{|l|r|r|c|}
\hline \multicolumn{1}{|c|}{ Groups } & $\mathrm{N}$ & $\begin{array}{l}\text { Correlation } \\
\text { Coefficient }\end{array}$ & P-value \\
\hline CIS 113 all and CIS 114 all & 2454 & .005 & .787 \\
\hline CIS 113 DL and CIS 114 DL & 361 & .014 & .791 \\
\hline CIS 113 FTF and CIS 114 FTF & 2,093 & .005 & .803 \\
\hline CIS 113 DL and CIS 114 FTF & 31 & .078 & .681 \\
\hline CIS 113 FTF and CIS 114 DL & 128 & .236 & $.007^{*}$ \\
\hline
\end{tabular}

As seen from the table, there is a weak to moderate statistically significant correlation between the grades of the students who took CIS 113 in face-to-face mode and CIS 114 in distance learning mode. All other groups in the table are not correlated. Tables 2 and 3 analyze differences between various groups' grades on CIS 113 and CIS 114 courses.

1 The two-tailed $\mathrm{P}$ value is less than 0.001

Proceedings of the 2002 American Society for Engineering Education Annual Conference \& Exposition Copyright (C) 2002, American Society for Engineering Education 
Table 2. Test of significance ${ }^{2}$ of differences in students' performance (mean grades) in CIS 113 and 114 courses in FTF and DL modes.

\begin{tabular}{|l|l|r|r|r|r|r|l|}
\hline & \multicolumn{1}{|c|}{ Group } & N & Mean & SD & SEM & P & Type of Data \\
\hline 1 & FTF (113+114) & 4945 & 2.168 & 1.53 & .022 & $<.0001 *$ & Scores \\
& DL (113+114) & 798 & 1.548 & 1.683 & .060 & & Scores \\
\hline 2 & FTF 113 & 2852 & 2.145 & 1.525 & .029 & $<.0001 *$ & Scores \\
& DL 113 & 437 & 1.573 & 1.662 & .079 & & Scores \\
\hline 3 & FTF 114 & 2093 & 2.198 & 1.537 & .034 & $<.0001 *$ & Scores \\
& DL 114 & 361 & 1.518 & 1.71 & .090 & & Scores \\
\hline
\end{tabular}

Table 3. Test of significance ${ }^{4}$ of differences in students' performance (mean grades) in CIS 113 and 114 courses for students who took the two courses in different modes. Asterisks denote groups with statistically significant correlations.

\begin{tabular}{|c|c|c|c|c|c|c|c|}
\hline & Group & $\mathrm{N}$ & Mean & SD & $\mathrm{SEM}^{5}$ & $P$ & Type of Data \\
\hline 4 & $\begin{array}{l}\text { FTF } 113 \\
\text { DL } 114\end{array}$ & $\begin{array}{l}128 \\
128\end{array}$ & $\begin{array}{l}2.352 \\
0.871\end{array}$ & $\begin{array}{l}1.365 \\
1.336\end{array}$ & .121 & $<.0001 *$ & $\begin{array}{l}\text { Scores of students who } \\
\text { took CIS } 113 \text { in FTF mode } \\
\text { and CIS } 114 \text { in DL mode }\end{array}$ \\
\hline 5 & $\begin{array}{l}\text { FTF } 114 \\
\text { DL } 113\end{array}$ & $\begin{array}{l}31 \\
31\end{array}$ & $\begin{array}{l}1.79 \\
2.29\end{array}$ & $\begin{array}{l}1.575 \\
1.537\end{array}$ & .283 & .197 & $\begin{array}{l}\text { Scores of students who } \\
\text { took CIS } 113 \text { in DL mode } \\
\text { and CIS } 114 \text { in FTF mode }\end{array}$ \\
\hline
\end{tabular}

\section{Discussion}

In most cases, data analysis did not find any statistically significant correlations between mode of learning and student performance. The only statistically significant correlation was between the performance of those students who took CIS 113 in FTF mode and then CIS 114 in DL mode. Data indicate that those students performed at the same level as other FTF students in the CIS 113 course; however, they performed worse in CIS 114 than those students who took both courses in DL mode ${ }^{6}$ and had significantly lower level of performance in CIS 114 than FTF

2 Tests 1-3 were unpaired two-tailed t-test for means.

* The results are statistically significant.

3 Standard error of means

4 Tests 4 and 5 were paired two-tailed t-test for means.

5 Standard error of means

6 The two-tailed $P$ value is less than 0.05

$*$ The results are statistically significant. 
students. This finding has implications for academic advisers who might recommend that students take both sequence courses in one mode only, either FTF or DL.

There was significant difference between FTF and DL student passing rates (percentage of students who received grades ' $A$ ' through ' $D$ ') on the same course; however, this difference is mostly accounted for by the number of withdrawals from the course (29 percent for DL compared to 16 percent FTF). Further analysis found that 62 percent of those DL students who withdrew from the course and then repeated it, passed the course with the grade ' $C$ ' or higher. At the same time, only 39 percent of the FTF students who withdrew from the course and then repeated it, passed the course with the grade ' $\mathrm{C}$ ' or higher. This finding gives reason to assume that lower passing rates of DL students are linked to non-academic reasons, such as full-time employment, computer problems, or excessive course load.

The study found differences in student performance based on faculty teaching styles and experience. More than half of instructors have kept their student passing rates between 70 and 80 percent consistently for the last six years. For the other instructors, student passing rates varied from 49 to 99 percent. Although the variances in passing rates were mostly attributed to the number of withdrawals from the course, there were also differences in teaching styles and pedagogy that were reflected in students' evaluations.

\section{Summary}

The study found statistically significant variances in face-to-face and distance learning student performance in the CIS 113 and CIS 114 courses. Distance learning students had higher SAT scores than their face-to-face counterparts, but their cumulative GPA was lower. No correlation was found between SAT scores and student grades in either course, and no correlation was found between grades in the two courses when taken via the same mode of delivery. Students in the face-to-face sections of each course performed better than students in the distance learning sections, achieving average course grades more than one-half letter grade higher. The grade differences are statistically significant. Further analysis, however suggested that the mode of study is not correlated with student performance. The difference is partially explained by the variances in instructors' teaching methodologies. There might be also some other, non-academic reasons for this difference; thus, additional studies are required to find the explanation. Those should be qualitative and quantitative studies that will match survey data with students' outcomes.

One of the most important findings of the study is that students perform better if they take CIS 114 in the same mode as CIS 113. Taking both of these courses in either FTF or DL modes produce better results than using FTF mode for one course and DL mode for the other.

Bibliography

1. Russell, T. The No Significant Difference Phenomenon, North Carolina State University, 1999.

2. Carpinelli, J., and Briller, V. "Distance Learning Instruction: As Effective as Faceto-face Instruction?" Proceedings of the International Conference on Engineering Education, Oslo, Norway, August 2001, pp. 6E8.8-10. 


\section{JOHN D. CARPINELLI}

John D. Carpinelli is an associate professor of Electrical and Computer Engineering, and Computer and Information Sciences, at New Jersey Institute of Technology. His research interests include interconnection networks, computer architecture, parallel processing, distance learning, and computer simulation. He is the author of the textbookComputer Systems Organization and Architecture (Addison-Wesley, 2001).

\section{VLADIMIR BRILLER}

Vladimir Briller received Ed.D. from Columbia University in 1995. He worked as an Associate Project Director at Education Development Center International Department in New York and as a Research Project Director at Vera Institute of Justice in New York evaluating various programs in the US and Europe. Currently he is a Director of the Outcomes Assessment at NJIT. 